\title{
Effect of aluminum addition on electrical properties, dielectric characteristics, and its stability of (Pr, Co, Cr, Y)- added zinc oxide-based varistors
}

\author{
CHOON-W NAHM \\ Department of Electrical Engineering, Dongeui University, Busan 614-714, Republic of Korea
}

MS received 25 January 2009; revised 7 April 2009

\begin{abstract}
The electrical properties, dielectric characteristics, and its stability against d.c. accelerated aging stress of $(\mathrm{Pr}, \mathrm{Co}, \mathrm{Cr}, \mathrm{Y})$-added zinc oxide-based varistors were investigated for different aluminum concentrations under a sintering temperature of $1280^{\circ} \mathrm{C}$. As the aluminum concentration increased, the average grain size (d) increased in the range of $4 \cdot 3-5.5 \mu \mathrm{m}$ and the sintered density increased in the range of $5.63-5.67 \mathrm{~g} / \mathrm{cm}^{3}$. As the aluminum concentration increased, the breakdown field decreased in the range of $6327-710 \mathrm{~V} / \mathrm{cm}$ and the maximum nonlinear coefficient (46.9) was obtained for $0.005 \mathrm{~mol} \%$ in aluminum concentration, further additions impaired the nonlinear properties. As the aluminum concentration increased, the apparent dielectric constant increased in the range of 500.5-1327.4 and dissipation factor increased in the range of 0.00493-0.0724. The varistor added with $0.001 \mathrm{~mol} \% \mathrm{Al}$ exhibited the highest stability for $E-J$ characteristics in which $\% \Delta E_{1 \mathrm{~mA}}$ is $+1.4 \%$ and $\% \Delta \alpha$ is $-5.7 \%$, under stress state of $0.95 E_{1 \mathrm{~mA}} / 150^{\circ} \mathrm{C} / 24 \mathrm{~h}$.
\end{abstract}

Keywords. Aluminum; electrical properties; dielectric characteristics; varistors; stability.

\section{Introduction}

Semiconductor ceramics are mainly used to fabricate the electronic devices using an electrostatic potential barrier at the grain boundary of ceramics. Among them, the varistor is a very smart electroceramic device, where the voltage-current properties are highly nonlinear. Pure zinc oxide ceramics exhibit linear properties even at any sintering condition, whereas the zinc oxide added with impurity exhibits nonlinear properties, which give rise to the decrease of impedance with increasing voltage. This nonlinearity of current-voltage properties is due to the presence of a double Schottky barrier formed at the active grain boundaries. Owing to highly nonlinear properties, zinc oxide varistors are extensively used in the field of surge protection systems from electronic circuits to electric power systems (Levison and Phillip 1986; Gupta 1990). Zinc oxide varistors are generally divided into two categories, called Bi-based and Pr-based ceramics, in terms of varistor forming oxides. The majority of commercial varistors is Bi-based varistors, which are added with many dopants. Zn-Bi-based ceramics show excellent nonlinear properties, however, $\mathrm{Bi}$ easily reacts with some metals used in preparing multilayer chip nonlinear ceramics, and it destroys the multilayer structure (Lee and Tseng 1992). And the stability against aging stress or electrostatic is

(cwnahm@deu.ac.kr) somewhat weak compared with Pr-based varistors. Recently, Zn-Pr-based ceramics have been studied in order to improve a few drawbacks associated with Bi (Alles and Burdick 1991; Lee et al 1996; Chun et al 1999; Nahm et al 2000; Chun and Mizutani 2001). Nahm et al reported that the quaternary system $\mathrm{ZnO}-\mathrm{Pr}_{6} \mathrm{O}_{11}-\mathrm{CoO}-$ $\mathrm{Cr}_{2} \mathrm{O}_{3}$ (ZPCC)-based varistors have highly nonlinear properties when Er, Y, Dy, La, and Tb are added (Nahm 2006, 2007; Nahm and Ryu 2002; Nahm et al 2003, 2004).

It is very important to comprehend the additivesdoping effect on electrical properties and its stability of the varistors. Aluminum is often added to $\mathrm{Zn}$-Bi-based varistors to improve the performance (Nunes and Bradt 1995; Wang et al 2006; Bernik and Daneu 2007). However, the role of aluminum in the $\mathrm{Zn}$-Pr-based varistors was found to partially differ from the $\mathrm{Zn}$-Bi-based varistors in a few respects.

In this study, the effect of aluminum addition on electrical properties, dielectric characteristics, and its stability against d.c. accelerated aging stress of $(\mathrm{Pr}, \mathrm{Co}, \mathrm{Cr}, \mathrm{Y})$-added zinc oxide-based varistors was investigated under a sintering temperature of $1280^{\circ} \mathrm{C}$. Some new results are reported.

\section{Experimental}

\subsection{Sample preparation}

Reagent-grade raw materials were used for preparing the varistors with a composition of $(97.5-x) \mathrm{mol} \% \mathrm{ZnO}$, 

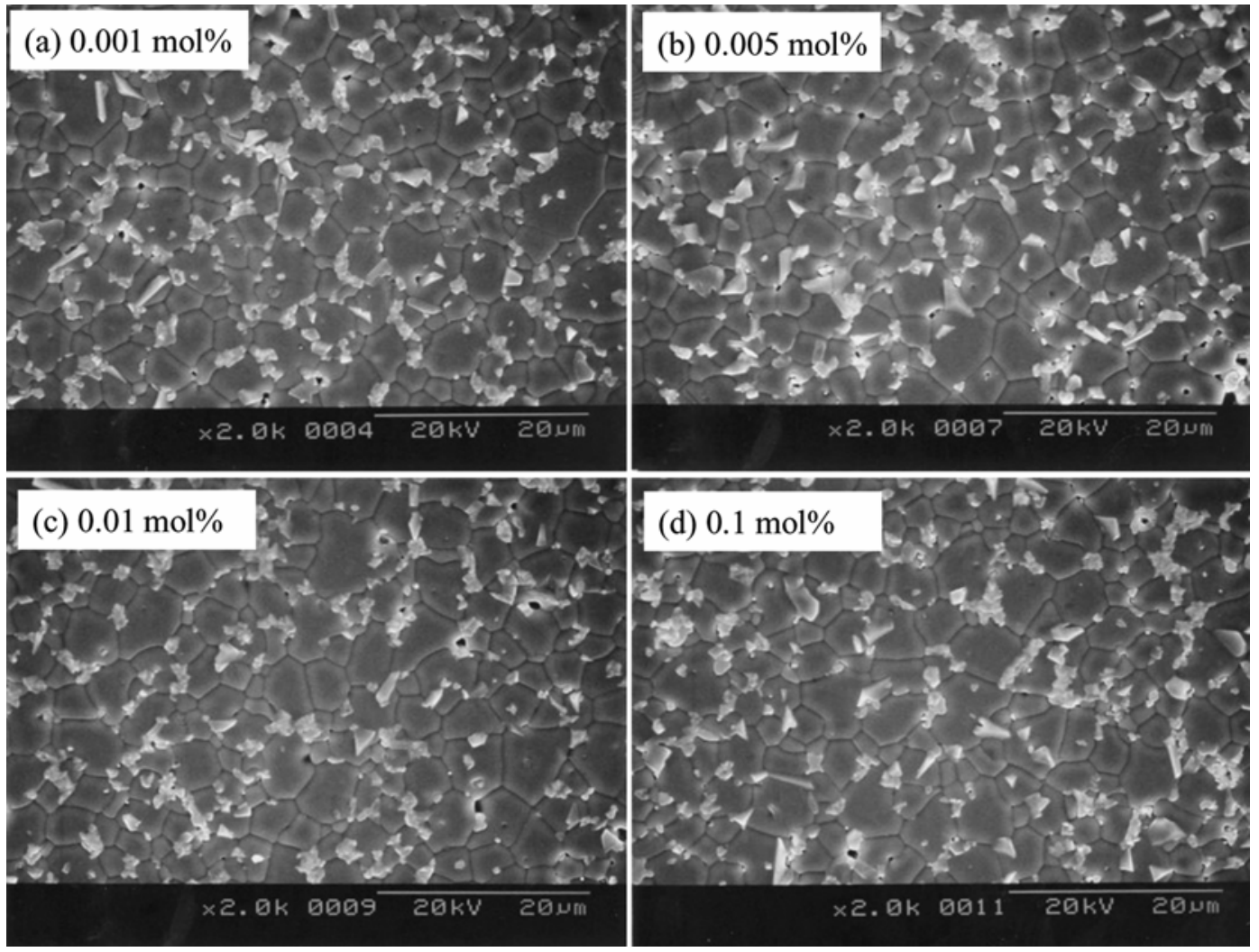

Figure 1. SEM micrographs of the samples for different concentrations of aluminum.

$0.5 \mathrm{~mol} \% \quad \mathrm{Pr}_{6} \mathrm{O}_{11}, \quad 1.0 \mathrm{~mol} \% \quad \mathrm{CoO}, \quad 0.5 \mathrm{~mol} \% \quad \mathrm{Cr}_{2} \mathrm{O}_{3}$, $0.5 \mathrm{~mol} \% \mathrm{Y}_{2} \mathrm{O}_{3}, x \mathrm{~mol} \% \mathrm{Al}_{2} \mathrm{O}_{3}(x=0.001,0.005,0.01$, $0 \cdot 1)$. Raw materials were mixed by ball milling with zirconia balls and acetone in a polypropylene bottle for $24 \mathrm{~h}$. The mixture was dried at $120^{\circ} \mathrm{C}$ for $12 \mathrm{~h}$ and calcined in air at $750^{\circ} \mathrm{C}$ for $2 \mathrm{~h}$. The calcined mixture was pulverized using an agate mortar/pestle and after $2 \mathrm{wt} \%$ polyvinyl alcohol (PVA) binder addition, granulated by sieving 100-mesh screen to produce the starting powder. The powder was uniaxially pressed into discs of $10 \mathrm{~mm}$ in diameter and $2 \mathrm{~mm}$ in thickness at a pressure of $800 \mathrm{~kg} /$ $\mathrm{cm}^{2}$. The discs were covered with raw powder in alumina crucible, sintered at $1280^{\circ} \mathrm{C}$ for $1 \mathrm{~h}$ and furnace cooled to room temperature. The sintered samples were lapped and polished to $1.0 \mathrm{~mm}$ thickness. The final samples were about $8 \mathrm{~mm}$ in diameter and $1.0 \mathrm{~mm}$ in thickness. Silver paste was coated on both faces of the samples and the electrodes were formed by heating at $600^{\circ} \mathrm{C}$ for $10 \mathrm{~min}$. The electrodes were $5 \mathrm{~mm}$ in diameter.

\subsection{Microstructure measurement}

Both surfaces of the samples were lapped and ground with $\mathrm{SiC}$ paper and polished with $\mathrm{Al}_{2} \mathrm{O}_{3}$ powder to a mirrorlike surface. The polished samples were thermally etched at $1100^{\circ} \mathrm{C}$ for $30 \mathrm{~min}$. The surface microstructure was examined by a scanning electron microscope (SEM,
Hitachi S2400, Japan). The average grain size (d) was determined by the lineal intercept method such as the following equation (Wurst and Nelson 1972):

$$
d=1.56 L / M N
$$

where $L$ is the random line length on the micrograph, $M$ the magnification of the micrograph, and $N$ the number of the grain boundaries intercepted by lines. The sintered density $(\rho)$ was measured using a density determination kit (238490) attached to balance (Mettler, AG 245).

\subsection{E-J characteristics measurement}

The electric field-current density $(E-J)$ characteristics were measured using a high voltage source/measure unit (Keithley 237). The breakdown field $\left(E_{1 \mathrm{~mA}}\right)$ was measured at $1.0 \mathrm{~mA} / \mathrm{cm}^{2}$ and the leakage current density $\left(J_{\mathrm{L}}\right)$ was defined as the current at $0.80 E_{1 \mathrm{~mA}}$. In addition, the nonlinear coefficient $(\alpha)$ is defined by the empirical law, $J=K \cdot E^{\alpha}$, where $J$ is the current density, $E$ the applied electric field, and $K$ a constant. The $\alpha$ was determined in the current density range of $1.0 \mathrm{~mA} / \mathrm{cm}^{2}$ to $10 \mathrm{~mA} / \mathrm{cm}^{2}$, where $\alpha=1 /\left(\log E_{2}-\log E_{1}\right)$, and $E_{1}$ and $E_{2}$ are the electric fields corresponding to $1.0 \mathrm{~mA} / \mathrm{cm}^{2}$ and $10 \mathrm{~mA} / \mathrm{cm}^{2}$, respectively. 


\subsection{D.C. accelerated aging characteristics} measurement

The dielectric characteristics, such as the apparent dielectric constant $\left(\varepsilon_{\mathrm{APP}}{ }^{\prime}\right)$ and dissipation factor $(\tan \delta)$ were measured in the range $100 \mathrm{~Hz}-2 \mathrm{MHz}$ using an RLC meter (QuadTech 7600).

\subsection{D.C. accelerated aging characteristics measurement}

The stability against d.c. accelerated aging stress was performed under four continuous states: (i) the first stress: $0.85 E_{1 \mathrm{~mA}} / 115^{\circ} \mathrm{C} / 24 \mathrm{~h}$, (ii) the second stress: $0.90 E_{1 \mathrm{~mA}} /$ $120^{\circ} \mathrm{C} / 24 \mathrm{~h}$, (iii) the third stress: $0.95 E_{1 \mathrm{~mA}} / 125^{\circ} \mathrm{C} / 24 \mathrm{~h}$ and (iv) the fourth stress: $0.95 E_{1 \mathrm{~mA}} / 150^{\circ} \mathrm{C} / 24 \mathrm{~h}$.

Simultaneously, the leakage current during the stress time was monitored at intervals of $1 \mathrm{~min}$ by a high voltage source-measure unit (Keithley 237). The varistors stressed were applied to the electrical characteristics after storage at normal room temperature for $2 \mathrm{~h}$. The degradation rate coefficient $\left(K_{\mathrm{T}}\right)$ was calculated from the following equation (Fan and Freer 1994):

$$
I_{\mathrm{L}}=I_{\mathrm{Lo}}+K_{\mathrm{T}} t^{1 / 2},
$$

where $I_{\mathrm{L}}$ is the leakage current at stress time $(t)$ and $I_{\mathrm{Lo}}$ is $I_{\mathrm{L}}$ at $t=0$. After applying the respective stresses, the $E-J$ characteristics were measured at room temperature.

\section{Results and discussion}

Figure 1 shows the SEM micrographs of the samples for different concentrations of aluminum. For all the samples, the X-ray diffraction (XRD) patterns (not shown) revealed the presence of a Pr-rich and Y-rich intergranular layer (whitish) as a minor secondary phase, in addition to a major phase of hexagonal $\mathrm{ZnO}$ (blackish). It can be seen that the microstructure is very simple as only two phases regardless of aluminum concentration. It is well known that this is one of the important features in Pr-based zinc oxide varistors (Mukae 1987). No $\mathrm{ZnAl}_{2} \mathrm{O}_{4}$ spinel phase related to aluminum was detected. Therefore, it is assumed that the majority of the aluminum atoms are dissolved into $\mathrm{ZnO}$ matrix, because positive trivalent aluminum ionic radius is smaller than that of positive divalent zinc. The average grain size $(d)$ increased from 4.3 to $5.5 \mu \mathrm{m}$ with the increase of aluminum concentration. As a result, aluminum was found to prompt the grain growth. If $\mathrm{ZnAl}_{2} \mathrm{O}_{4}$ of spinel phase was formed, the grain average size should be reduced due to the restriction of zinc oxide grain growth. The sintered density $(\rho)$ slightly increased from $5.63-5.67 \mathrm{~g} / \mathrm{cm}^{3}$ corresponding to $97.4-98 \cdot 1 \%$ of theoretical density $\left(5.78 \mathrm{~g} / \mathrm{cm}^{3}\right.$ for zinc oxide). It can be seen that the densification was not nearly affected by aluminum addition. However, it should be noted that the behaviour of the grain size and sintered density with the increase of aluminum concentration showed opposite results compared with Bi-based zinc oxide varistors (Nunes and Bradt 1995; Wang et al 2006; Bernik and Daneu 2007). The detailed microstructural parameters are summarized in table 1.

Figure 2 shows the electric field-current density $(E-J)$ characteristics of the samples for different concentrations of aluminum. The curves show the conduction characteristics divided into two regions: a linear region before the breakdown field and a nonlinear region after the breakdown field. The linear region below breakdown field is dominated by the thermionic emission over the Schottky barrier. The nonlinear region above breakdown field is predominated by the field emission through the Schottky barrier. The sharper the knee of the curves between the two regions, the better the nonlinear properties. On adding more aluminum, the knee gradually becomes less pronounced and as a result, the nonlinear properties are impaired. Therefore, an appropriate addition of aluminum seems to enhance nonlinear properties, whereas an excess addition results in bad nonlinear properties, as shown in figure 2(d).

Figure 3 shows breakdown field $\left(E_{1 \mathrm{~mA}}\right)$ and nonlinear coefficient $(\alpha)$ of the samples for different concentrations of aluminum. The $E_{1 \mathrm{~mA}}$ decreased from 6327 to $710 \mathrm{~V} / \mathrm{cm}$ with the increase of concentration of aluminum. This is attributed to the decrease of number of the grain boundaries, which is caused by the increase of the $\mathrm{ZnO}$ grain size. The breakdown field of varistor directly depends on the grain size between electrodes because the varistor is a thickness device, $V_{\mathrm{B}}=n_{\mathrm{gb}} \cdot v_{\mathrm{gb}}=(D / d) v_{\mathrm{gb}}$, where $V_{\mathrm{B}}$ is the breakdown voltage, $n_{\mathrm{gb}}$ the number of grain boundaries, $d$ the average grain size, and $D$ thickness of sample. The varistors added with $\mathrm{Al}_{2} \mathrm{O}_{3}$ having more than $0.1 \mathrm{~mol} \%$ exhibited much lower $v_{\mathrm{gb}}(0.4 \mathrm{~V} / \mathrm{gb})$ value than a general value of $2-3 \mathrm{~V} / \mathrm{gb}$. It is presumed

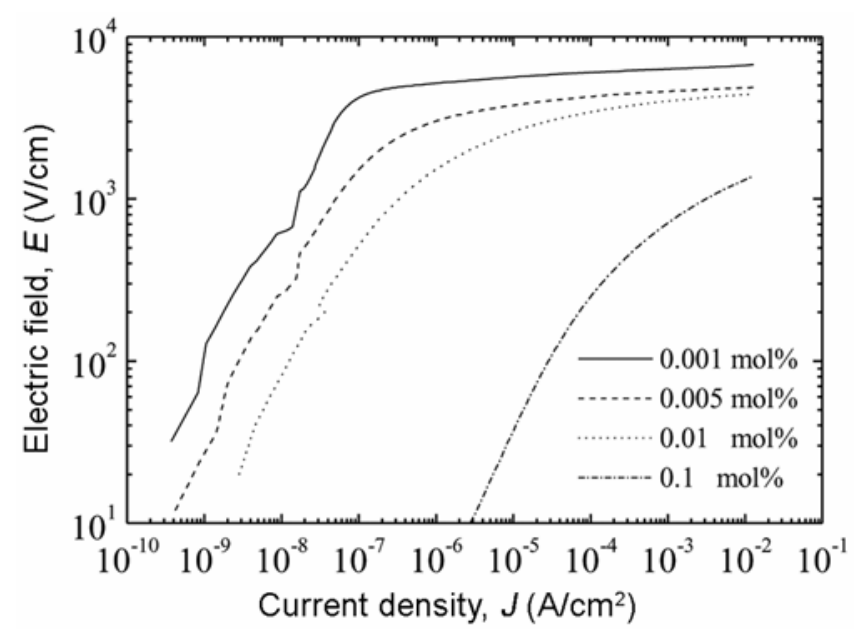

Figure 2. $E-J$ characteristics of the samples for different concentrations of aluminum. 
that these samples will exhibit very poor non-ohmic properties due to low electrostatic potential barrier at grain boundary. It should be noted that the behaviour of $E_{1 \mathrm{~mA}}$ showed different results in comparison to $\mathrm{ZnO}-\mathrm{Bi}$-based samples (Wang et al 2006; Bernik and Daneu 2007).

The nonlinear coefficient $(\alpha)$ is figure merit, which is related to the proportion of Schottky emission electrons to field emission electrons in terms of the conduction electron with increasing electric field. The great proportion leads to high $\alpha$. The $\alpha$ slightly increased from $43.7-$ 46.9 with the increase of concentration of aluminum at $<0.005 \mathrm{~mol} \%$. However, further additions greatly decreased it and $\alpha$ was only 4 at $0.1 \mathrm{~mol} \%$. Although aluminum concentration of $0.1 \mathrm{~mol} \%$ compared with the usual additives is never high in concentrations, it greatly impaired the nonlinear properties. The leakage current $\left(I_{\mathrm{L}}\right)$ increased from $0.1 \mu \mathrm{A}$ to $0.1 \mathrm{~mA}$ with the increase of concentration of aluminum. This is attributed to the increase of electron concentration by substitution of $\mathrm{Al}$ for $\mathrm{Zn}$ site. It was confirmed that aluminum has a strong effect on the nonlinear properties. It is assumed that aluminum doping effect on nonlinear properties is related to the electronic state at the grain boundary. The detailed $E-J$ characteristic parameters are summarized in table 1 .

Figure 4 shows dielectric characteristics of the samples for different concentrations of aluminum. The apparent dielectric constant $\left(\varepsilon_{\mathrm{APP}}{ }^{\prime}\right)$ decreased gradually with increasing frequency for all samples. The $\varepsilon_{\mathrm{APP}}$ is associated with the dielectric polarization through entire ceramics. The $\varepsilon_{\mathrm{APP}}{ }^{\prime}$ in the measuring frequency range increases in the range of $500 \cdot 5-1327.4$ at $1 \mathrm{kHz}$ with the increase of aluminum concentration. This is directly related to the average grain size, as can be seen in the following equation,

$$
\varepsilon_{\mathrm{APP}^{\prime}}=\varepsilon_{\mathrm{g}}(d / t),
$$

where $\varepsilon_{\mathrm{g}}$ is the dielectric constant of $\mathrm{ZnO}, d$ the average grain size, and $t$ the depletion layer width (Levinson and

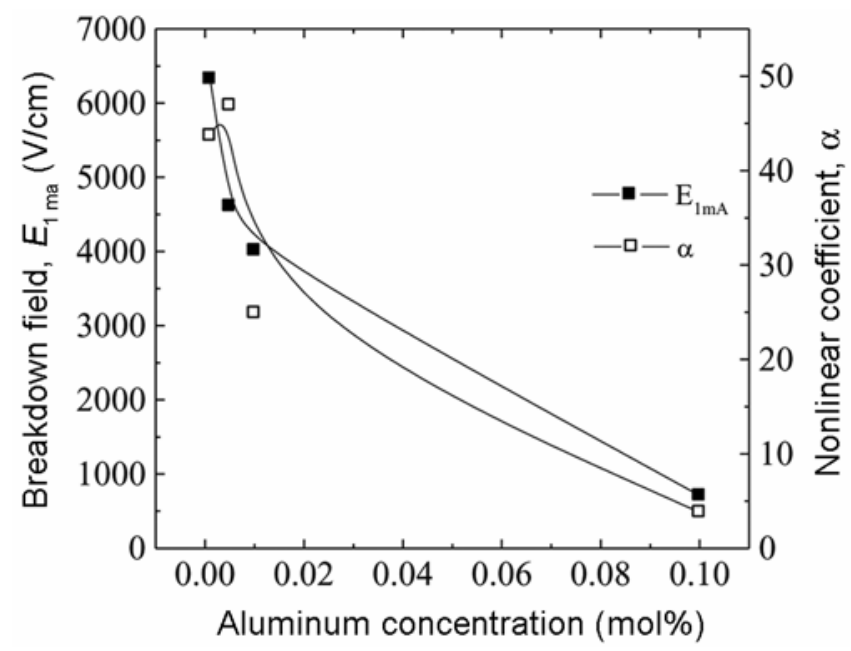

Figure 3. Breakdown field and nonlinear coefficient for different concentrations of aluminum.
Philipp 1986). The increase of aluminum concentration increases average grain size. This causes the decrease of effective depletion layer width within entire bulk. Therefore, the increase of aluminum concentration leads to the increase of $\varepsilon_{\mathrm{APP}}$. The detailed dielectric parameters, including the apparent dielectric constant $\left(\varepsilon_{\mathrm{APP}}{ }^{\prime}\right)$ and dissipation factor $(\tan \delta)$ are summarized in table 1. All curves of $\tan \delta$ exhibit a similar behaviour, whereas a complicated curve, is known as the dielectric dispersion phenomenon. In general, $\tan \delta$ decreased as frequency increased until a minimum was obtained. After a minimum, the $\tan \delta$ increased to maximum with increasing frequency and thereafter again decreased. The $\tan \delta$ of the varistors added with $\mathrm{Al}$ more than $0.005 \mathrm{~mol} \%$ follow general fact, as described above. However, the $\tan \delta$ of the varistor added with $0.001 \mathrm{~mol} \% \mathrm{Al}$ exhibited $\wedge$-shape curve, which again decreases after increase with increase of frequency. The $\tan \delta$ was increased in the range of $0.0493-0.0724$ at $1 \mathrm{kHz}$ with the increase of aluminum concentration. The $\tan \delta$ is composed of joule heating loss by leakage current and friction heating loss by electric dipole rotation. It is assumed that the increase of $\tan \delta$ is affected by the increase of leakage current $\left(I_{\mathrm{L}}\right)$, as indicated in figure 5. The abnormal dielectric dispersion may
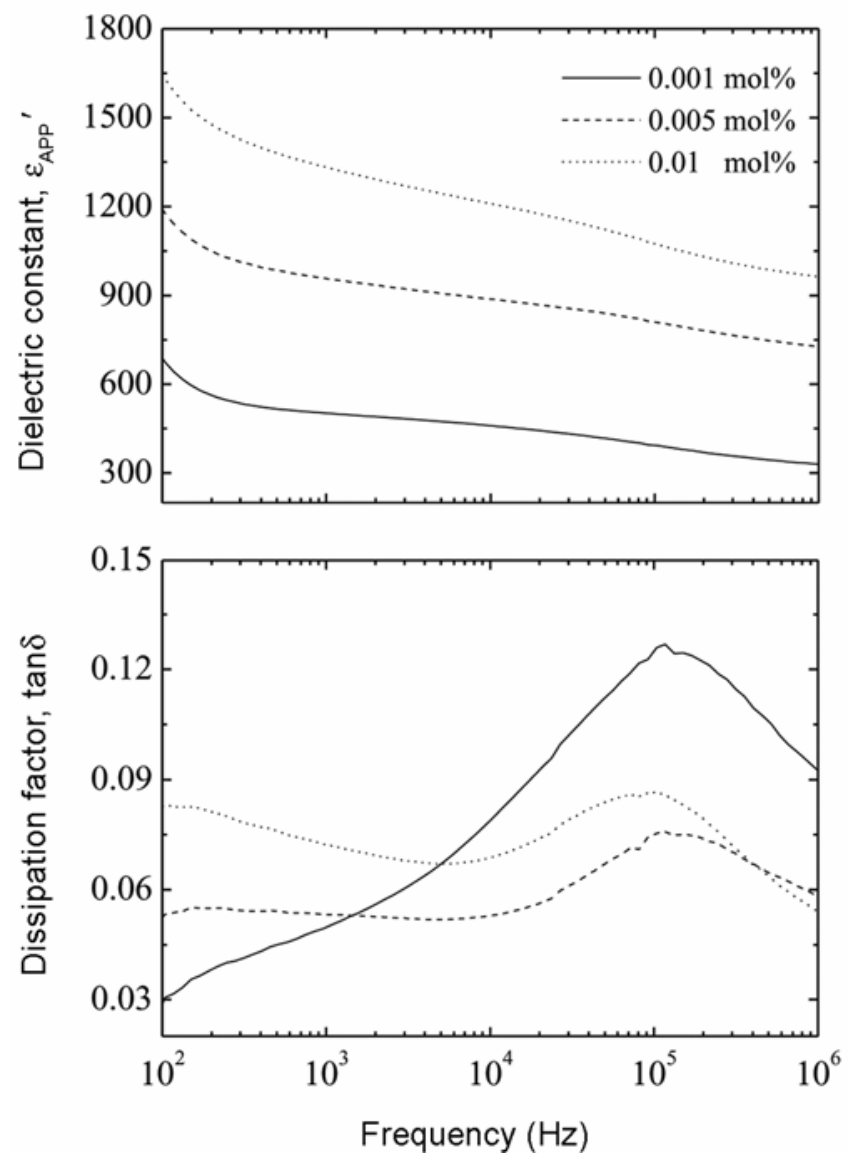

Figure 4. Dielectric characteristics of the samples for different concentrations of aluminum. 
Table 1. Microstructure, $E-J$ characteristics, and dielectric characteristic parameters of the samples for different concentrations of aluminum.

\begin{tabular}{lcccccccc}
\hline $\begin{array}{l}\text { Aluminum } \\
\text { concentration }(\mathrm{mol} \%)\end{array}$ & $d(\mu \mathrm{m})$ & $\rho\left(\mathrm{g} / \mathrm{cm}^{3}\right)$ & $E_{1 \mathrm{~mA}}(\mathrm{~V} / \mathrm{cm})$ & $v_{\mathrm{gb}}(\mathrm{V} / \mathrm{gb})$ & $\alpha$ & $I_{\mathrm{L}}(\mu \mathrm{A})$ & $\varepsilon_{\mathrm{APP}}{ }^{\prime}(1 \mathrm{kHz})$ & $\tan \delta(1 \mathrm{kHz})$ \\
\hline 0.001 & $4 \cdot 3$ & 5.63 & 6327 & 2.7 & $43 \cdot 7$ & $0 \cdot 1$ & $500 \cdot 5$ & 0.0493 \\
0.005 & $4 \cdot 8$ & 5.65 & 4610 & $2 \cdot 2$ & $46 \cdot 9$ & 1.4 & $954 \cdot 1$ & $0 \cdot 0532$ \\
0.01 & $5 \cdot 2$ & 5.66 & 4012 & $2 \cdot 1$ & 24.9 & $9 \cdot 7$ & $1327 \cdot 4$ & 0.0724 \\
$0 \cdot 1$ & $5 \cdot 5$ & 5.67 & 710 & 0.4 & $3 \cdot 8$ & $0 \cdot 1 \mathrm{~mA}$ & - & - \\
\hline
\end{tabular}

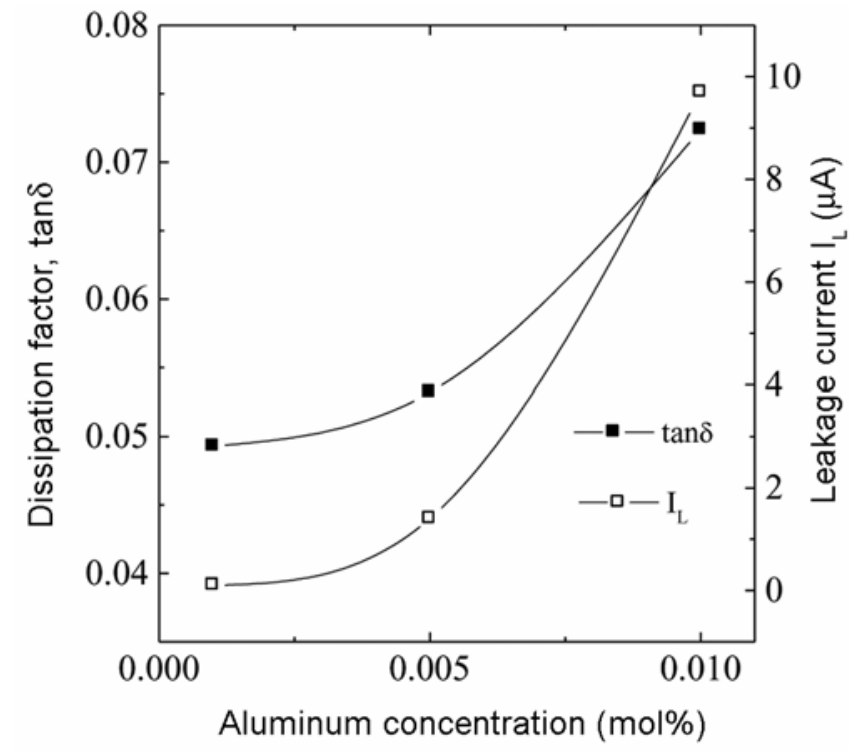

Figure 5. Dissipation factor and leakage current of the samples for different concentrations of aluminum.

not be seen clearly through $\varepsilon_{\mathrm{APP}}{ }^{\prime}$ curve, but it is assumed to be in the vicinity of $100 \mathrm{kHz}$ through the peak of $\tan \delta$. In general, the abnormal dispersion appears at peak of $\tan \delta$.

In practice, the varistors are always subjected to a continuous normal electrical stress, lightning surge, and switching surge. Under such surges, they are gradually degraded with time. Therefore, the high electrical stability against stress is very important in the light of reliability of various electrical and electronic systems.

Figure 6 shows the variation of leakage current during various d.c. accelerated aging stresses of the samples for different concentrations of aluminum. The varistor added with $0.001 \mathrm{~mol} \%$ Al exhibited nearly constant leakage current during stress period from the first to the third stress. The fourth stressed sample exhibited positive creep for leakage current (PCLC), where the leakage current gradually increases during stress. On the whole, this sample shows high stability against d.c. accelerated aging stress. The varistor added with $0.005 \mathrm{~mol} \% \mathrm{Al}$ exhibited nearly constant leakage current during stress period until the third stress, whereas it exhibited instability, which gives rise to thermal runaway within a short time at the fourth stress. The varistor added with $0.01 \mathrm{~mol} \% \mathrm{Al}$ exhibited
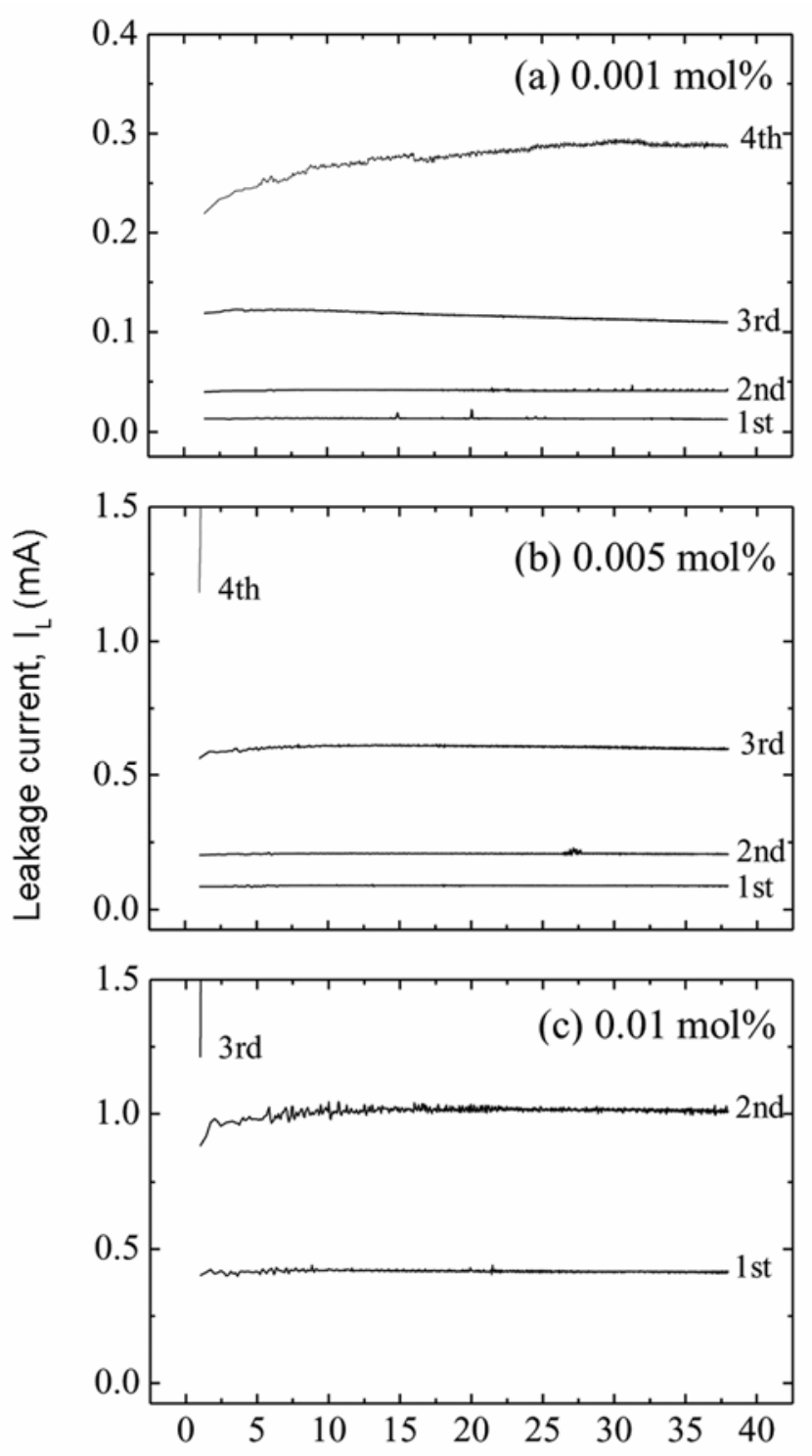

Accelerated aging stress time, $\mathrm{t}^{1 / 2}(\mathrm{~min})^{1 / 2}$

Figure 6. Leakage current during d.c. accelerated aging stress of the samples for different concentrations of aluminum.

nearly constant leakage current during stress period until the second stress, whereas it exhibited instability, which gives rise to thermal runaway within a short time at the third stress. 
Table 2. Variations of $E-J$ characteristic parameters before and after d.c. accelerated aging stress of the samples for different concentrations of aluminum.

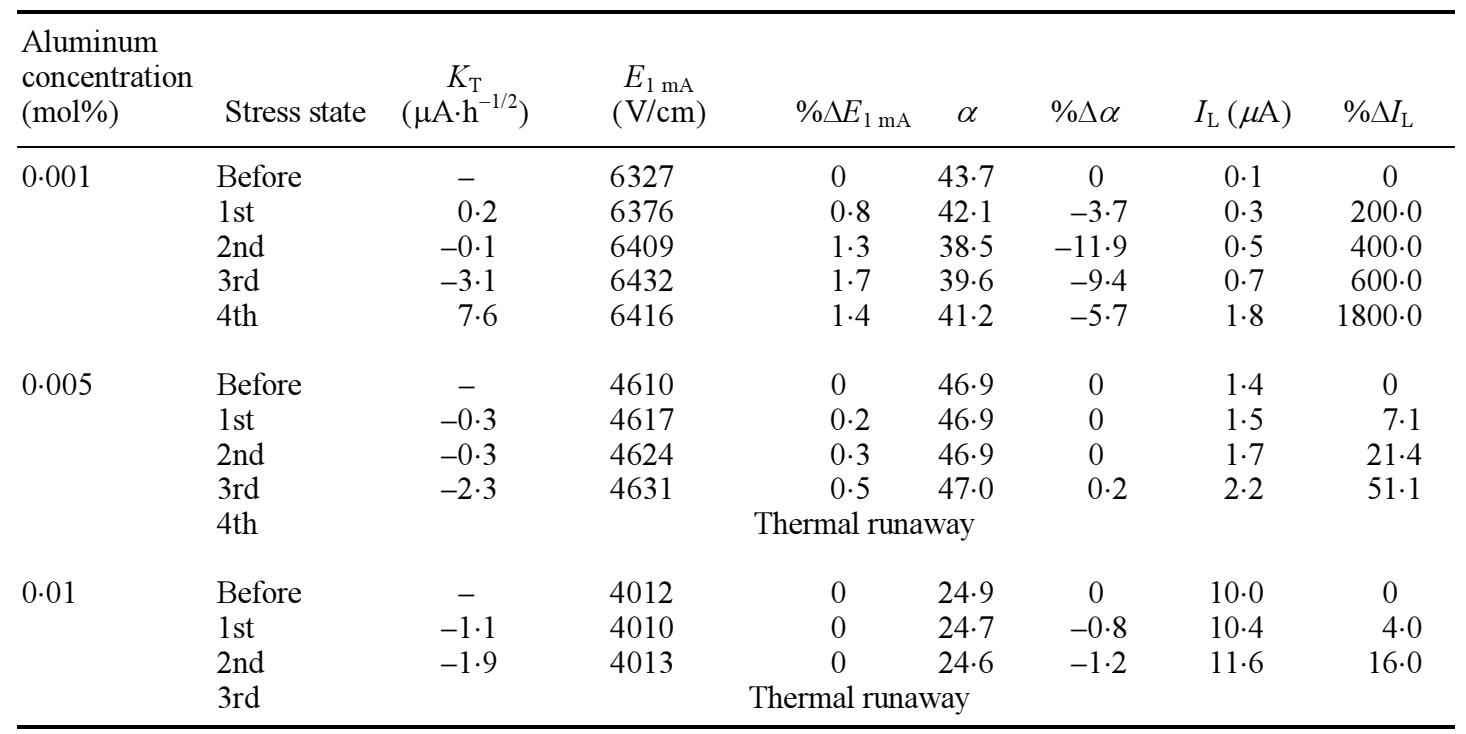

Table 3. Variations of dielectric characteristic parameters before and after d.c. accelerated aging stress of the samples for different concentrations of aluminum.

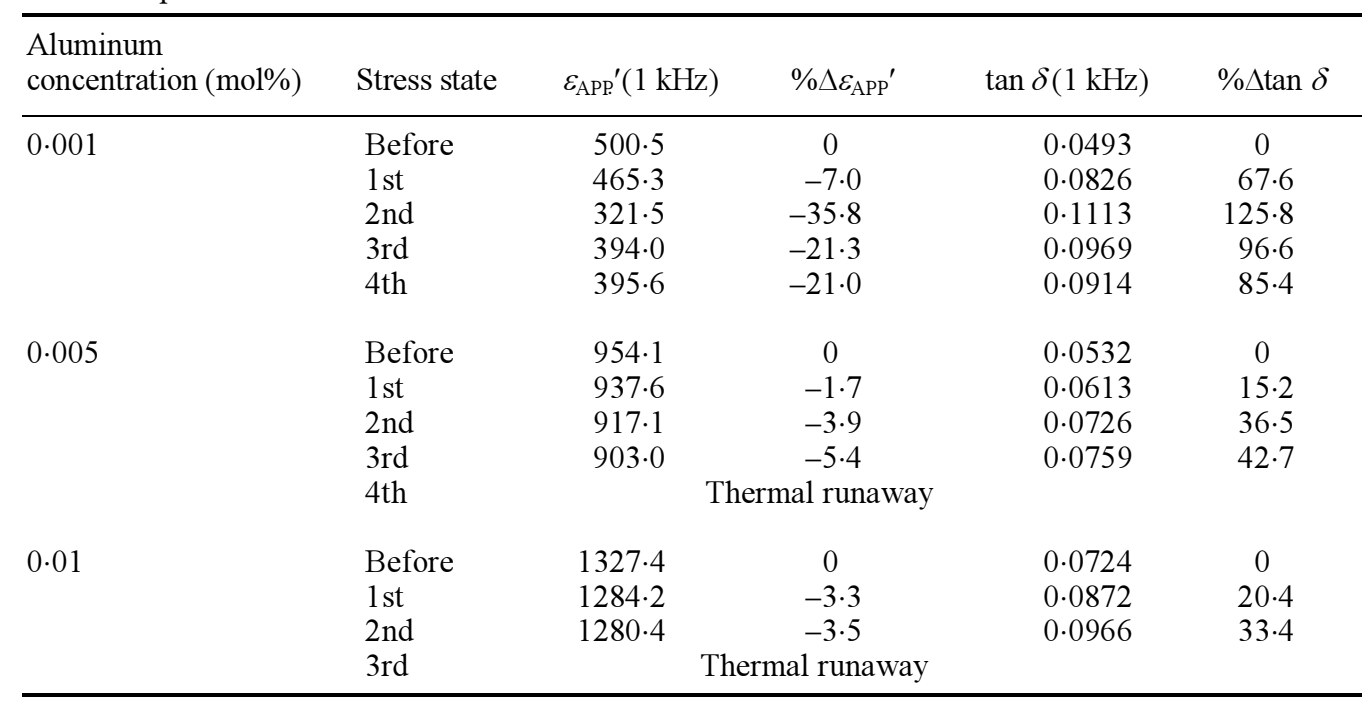

Figure 7 shows degradation coefficient $\left(K_{\mathrm{T}}\right)$ of the samples for different concentrations of aluminum. The stability of the samples can be estimated by the degradation rate coefficient $\left(K_{\mathrm{T}}\right)$, indicating the degree of aging. This exhibits a slope of leakage current for the stress time. The lower the $K_{\mathrm{T}}$ value, the higher the stability. The varistors added with $0.005 \mathrm{~mol} \%$ and $0.01 \mathrm{~mol} \% \mathrm{Al}$ exhibited low $K_{\mathrm{T}}$ before thermal runaway. It can be seen that the stress strength has a significant effect on the resistance against d.c. accelerated aging stress with aluminum concentration.

The stability against d.c. accelerated aging stress exhibited to be impaired with the increase of aluminum concentration and the leakage current exhibited to be increased with the increase of aluminum concentration under the same stress condition. These experimental results can be explained as follows. Macroscopically, the sintered density and the leakage current are main factors, which affect the stability against d.c. stress. That is, the lower the sintered density and the higher the leakage current, the lower the stability. The low sintered density decreases the cross sectional area of conduction path at grain boundary and eventually leads to the concentration of current. The sintered density for all samples is not low enough to have an effect on the stability, whereas the leakage current exhibited large differences with the samples. The high leakage current gradually increases the carrier generation due to joule heat and it leads to repetition cycle between joule heating and leakage current. 


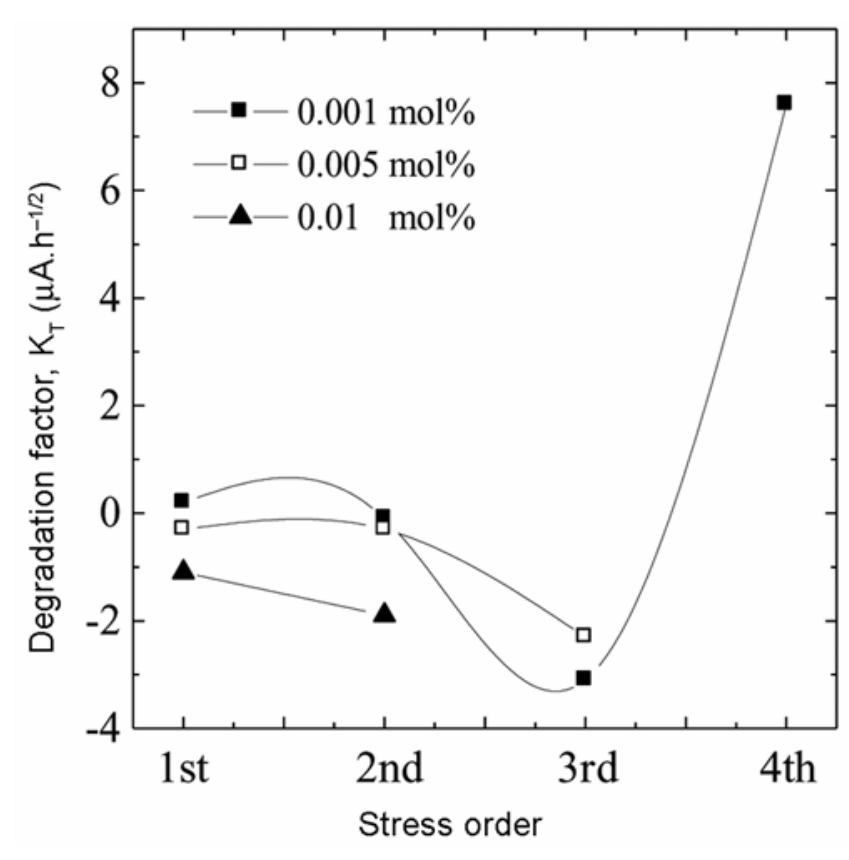

Figure 7. Degradation coefficient with d.c. accelerated aging stress of the samples for different concentrations of aluminum.

This is core for aging mechanism from a macroscopic viewpoint. It had been mentioned in the $E-J$ characteristics that the leakage current increases with the increase of aluminum concentration. On the whole, it can be seen that aluminum doping greatly stabilizes against d.c. accelerated aging stress. The variation of breakdown field $\left(\% \Delta E_{1 \mathrm{~mA}}\right)$, variation of nonlinear coefficient $(\% \Delta \alpha)$, and variation of leakage current $\left(\% \Delta I_{\mathrm{L}}\right)$ are summarized in table 2 . The varistor added with $0.001 \mathrm{~mol} \% \mathrm{Al}$ exhibited the high stability for $E-J$ characteristics, in which $\% \Delta E_{1 \mathrm{~mA}}$ is $+1.4 \%$ and $\% \Delta \alpha$ is $-5.7 \%$ after the fourth stress. This is compared with other Zn-Pr-based ceramics reported and more stable than $\mathrm{Zn}$-Bi-based ceramics (Fan and Freer 1995; Wang et al 2006). On the other hand, the variation of dielectric constant $\left(\% \Delta \varepsilon_{\mathrm{APP}}\right)$ and variation of dissipation factor $(\% \Delta \tan \delta)$ with d.c. accelerated aging stress are summarized in table 3 . For the varistor added with $0.001 \mathrm{~mol} \% \mathrm{Al}$, the $\% \Delta \varepsilon_{\mathrm{APP}^{\prime}}$ and the $\% \Delta \tan \delta$ increased with the increase of stress strength until the second stress, and thereafter they were maintained almost constantly. In contrast, the varistor added with $0.005 \mathrm{~mol} \%$ $\mathrm{Al}$ exhibited smaller $\% \Delta \varepsilon_{\mathrm{APP}}{ }^{\prime}$ and $\% \Delta \tan \delta$ than those of the varistor added with $0.001 \mathrm{~mol} \%$ Al before thermal runaway at the fourth stress. On the whole, unlike $E-J$ characteristics, these samples exhibited the high variation for dielectric characteristics. The $\% \Delta \varepsilon_{\mathrm{APP}}{ }^{\prime}$ and $\% \Delta \tan \delta$ of the varistor added with $0.001 \mathrm{~mol} \% \mathrm{Al}$ were $-21.4 \%$ and $+85.4 \%$, respectively after the fourth stress.

\section{Conclusions}

The effect of aluminum addition on electrical properties, dielectric characteristics, and its stability against d.c. accelerated aging stress of $(\mathrm{Pr}, \mathrm{Co}, \mathrm{Cr}, \mathrm{Y})$-added zinc oxide-based varistors was investigated under a sintering temperature of $1280^{\circ} \mathrm{C}$. The increase of aluminum concentration increased the average grain size in the range of 4.3-5.5 $\mu \mathrm{m}$, whereas it does not have an effect on sintered density. As the aluminum concentration increased, the breakdown field decreased in the range of 6327 to $710 \mathrm{~V} /$ $\mathrm{cm}$ due to the increase of grain size. The maximum nonlinear coefficient (46.9) was obtained for $0.005 \mathrm{~mol} \%$ in aluminum concentration, whereas further additions impaired the nonlinear properties. As the aluminum concentration increased, the apparent dielectric constant increased in the range of 500.5-1327.4 and the dissipation factor increased in the range of $0.00493-0.0724$. The varistor added with $0.001 \mathrm{~mol} \% \mathrm{Al}$ exhibited the highest stability for $E-J$ characteristics, in which $\% \Delta E_{1 \mathrm{~mA}}$ is $+1.4 \%$ and $\% \Delta \alpha$ is $-5.7 \%$ under a stress state of $0.95 E_{1 \mathrm{~mA}} /$ $150^{\circ} \mathrm{C} / 24 \mathrm{~h}$.

\section{References}

Alles A B and Burdick V L 1991 J. Appl. Phys. 706883

Bernik S and Daneu N 2007 J. Eur. Ceram. Soc. 273161

Chun S Y and Mizutani N 2001 Mater. Sci. Eng. B79 1

Chun S Y, Shinozaki K and Mizutani N 1999 J. Am. Ceram. Soc. 823065

Fan J and Freer R 1994 J. Am. Ceram. Soc. 772663

Fan J and Freer R 1995 J. Am. Ceram. Soc. 774795

Gupta T K 1990 J. Am. Ceram. Soc. 731817

Lee Y S and Tseng T Y 1992 J. Am. Ceram. Soc. 75 1636

Lee Y S, Liao K S and Tseng T Y 1996 J. Am. Ceram. Soc. 79 2379

Levinson L M and Philipp H R 1986 Am. Ceram. Soc. Bull. 65 639

Mukae K 1987 Am. Ceram. Soc. Bull. 661329

Nahm C W 2006 J. Mater. Sci. 417272

Nahm C W 2007 Mater. Sci. Eng. B137 112

Nahm C W and Ryu J S 2002 Mater. Lett. 53201

Nahm C W, Park C H and Yoon H S 2000 J. Mater. Sci. Lett. 19271,725

Nahm C W, Shin B C and Min B H 2003 Mater. Chem. Phys. 82157

Nahm C W, Park J A, Kim M J and Shin B C 2004 J. Mater. Sci. 39307

Nunes S I and Bradt R C 1995 J. Am. Ceram. Soc. 782469

Wang M H, Hu K A, Ahao B Y and Ahang N F 2006 Mater. Chem. Phys. 100142

Wurst J C and Nelson J A 1972 J. Am. Ceram. Soc. 55109 